Akreditasi Ristekdikti,

No: 30/E/KPT/2019 (Sinta 4)

Paradigma,

DOI: https://doi.org/10.31294/p.v23i1.9758

Vol. 23, No. 1 Maret 2021

P-ISSN 1410-5063, E-ISSN: 2579-3500

\title{
Analisis Runtun Waktu Untuk Memprediksi Jumlah Mahasiswa Baru Dengan Model Arima
}

\author{
Ayu Ulfa Jamila ${ }^{1}$, Bella Merlin Siregar ${ }^{2}$, Roni Yunis ${ }^{3}$ \\ 1,2,3Program Studi Sistem Informasi, STMIK Mikrsokil Medan \\ e-mail: 172113993@students.mikroskil.ac.id ${ }^{1}$ \\ e-mail: 172112084@students.mikroskil.ac.id ${ }^{2}$ \\ e-mail: roni@mikroskil.ac.id ${ }^{3}$
}

\begin{abstract}
Abstrak - Peramalan penerimaan mahasiswa baru sangatlah penting bagi perguruan tinggi agar keputusan yang diambil perguruan tinggi dapat lebih optimal. Penelitian ini bertujuan untuk menemukan model terbaik agar dapat meramalkan jumlah mahasiswa baru untuk 5 tahun ke depan melalui analisis runtun waktu. Model yang digunakan dalam penelitian ini yaitu Model ARIMA (Autoregressive Integrated Moving Average) dengan dataset penerimaan mahasiswa baru Universitas XYZ periode 2010 sampai dengan 2019. Tahap pelaksanaan penelitian mengacu pada metode OSEMN yaitu Obtain data, Scrubbing data, Explore data, Modeling data, dan Intetpreting data. Hasil analisis menunjukkan bahwa model terbaik yaitu model ARIMA (2,1,1). Model ARIMA yang dihasilkan menunjukkan nilai MAPE sebesar 7.066147 dengan akurasi sebesar 93\%. Hasil peramalan menunjukkan bahwa terjadinya trend penurunan jumlah mahasiswa baru secara merata untuk 5 tahun kedepan.
\end{abstract}

Kata kunci: Peramalan, Jumlah Mahasiswa Baru, ARIMA, MAPE

\begin{abstract}
Forecasting new student admissions is very important for universities so that decisions made by universities can be more optimal. This study aims to find the best model in order to predict the number of new students for the next 5 years through time series analysis. The model used in this study is the ARIMA (Autoregressive Integrated Moving Average) Model with the new student admissions dataset for XYZ University for the period 2010 to 2019. The research implementation stage refers to the OSEMN method, namely Obtain data, Scrubbing data, Explore data, Modeling data, and Interpreting data. The analysis results show that the best model is the ARIMA model (2,1,1). The resulting ARIMA model shows a MAPE value of 7.066147 with an accuracy of $93 \%$. The forecast results show that there is a trend of decreasing the number of new students evenly for the next 5 years.
\end{abstract}

Keywords: Forecasting, Number of New Students, ARIMA, MAPE

\section{PENDAHULUAN}

Penerimaan mahasiswa baru adalah kegiatan utama dalam sebuah perguruan tinggi yang rutin dilakukan setiap tahunnya (Niswatin, 2016). Mahasiswa merupakan salah satu unsur yang penting dalam kegiatan pembelajaran di perguruan tinggi. Kini sudah banyak ditemukan perguruan tinggi yang berkualitas sehingga menyebabkan persaingan antara perguruan tinggi satu dengan yang lain. Maka diperlukannya tindakan untuk meningkatkan kualitas perguruan tinggi yang dapat dilakukan semaksimal mungkin.

Berbagai bentuk strategi dan cara sudah dilakukan oleh perguruan tinggi untuk mencapai target yang diinginkan. Tetapi beberapa strategi tersebut tidak tepat sasaran sehingga target, minat, dan kualitas calon mahasiswa baru tidak sesuai harapan. Untuk mengatasi hal tersebut salah satu hal yang bisa dilakukan perguruan tinggi adalah melakukan peramalan. Peramalan (Forecasting) merupakan kegiatan dalam memprediksi kejadian besar ataupun runtun waktu yang akan datang berdasarkan hasil data melalui pengujian keadaan di masa lalu sehingga dapat mempersiapkan tindakan untuk ke depannya (Achmanda, 2018).

Untuk melakukan peramalan dengan analisis runtun waktu dalam penelitian ini metode yang digunakan adalah ARIMA (Autoregressive Integrated Moving Average. ARIMA merupakan Salah satu metode peramalan yang sedang berkembang dan umum digunakan saat ini dan ARIMA memiliki kelebihan yaitu bersifat fleksibel, dan tingkat keakuratannya efektif sehingga tepat digunakan dalam peramalan jangka pendek dan hanya membutuhkan data historis dalam peramalannya (Muhammad et al., 2017).

Penelitian terdahulu terkait tentang peramalan diantaranya Wici Irawan (2019) "Peramalan Harga Saham PT. Unilever Tbk. Dengan Menggunakan Model ARIMA “ dan Siska Candra Ningsih dan Padrul Jana (2018) "Pemodelan Penderita HIV/AIDS dengan Metode ARIMA “. Mengingat pentingnya untuk mengetahui jumlah penerimaan 
mahasiswa Universitas XYZ di masa depan maka dilakukan peramalan jumlah penerimaan mahasiswa baru menggunakan metode ARIMA (Irawan, 2019) (Ningsih \& Jana, 2018).

\section{METODOLOGI PENELITIAN}

\section{Bahan Penelitian}

Data yang digunakan dalam penelitian ini diperoleh dari data penerimaan mahasiswa baru periode 2010 hingga 2019 Universitas XYZ. Data ini didapatkan dari bagian PSI Universitas XYZ dalam format file CSV dan datanya terdiri dari 9613 baris dan 11 kolom.

Tabel 1. Atribut dataset penerimaan mahasiswa baru

\begin{tabular}{|c|c|}
\hline Atribut & Isi Data \\
\hline Tahun.Akademik & $2017 / 2018$ \\
\hline Tanggal.Daftar & $31-08-2017$ \\
\hline Program.Studi & $\begin{array}{c}\text { SISTEM } \\
\text { INFORMASI }\end{array}$ \\
\hline Jumlah.Mhs & 2 \\
\hline Jumlah.Grade.A & 1 \\
\hline Jumlah.Grade.B & 0 \\
\hline Jumlah.Grade.C & 1 \\
\hline Jumlah.Grade.D & 0 \\
\hline Kode.Sekolah & 10220210 \\
\hline Nama.Sekolah & SMKN 9 MEDAN \\
\hline Nama.Kota & MEDAN \\
\hline
\end{tabular}

\section{Tahap Penelitian (OSEMN)}

Proses OSEMN merupakan model organisasi penelitian yang standar dan dapat diterima secara luas di bidang Data Science. Proses OSEMN juga dapat memecahkan masalah dengan Data Science/Analisis dalam skala besar (Dineva \& Atanasova, 2018). Tahapan OSEMN dapat dilihat pada Gambar 1 (Lau, 2019).

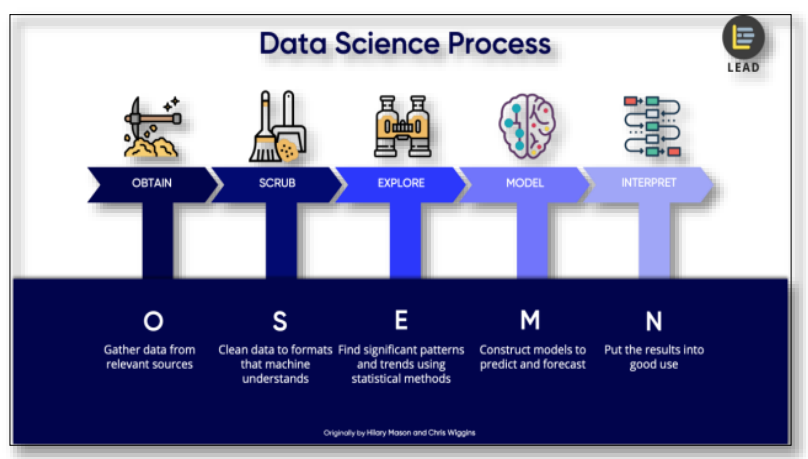

Sumber: (Lau, 2019)

Gambar 1. Proses OSEMN

\section{a. Obtain/Data Collection}

Dalam Data Science hal yang perlu dilakukan adalah mengumpulkan data. Dalam penelitian ini data yang diperoleh berasal dari data penerimaan mahasiswa baru dalam format file CSV. Jika menggunakan software R, di dalamnya terdapat paket khusus yang dapat membaca data dari sumber data ini langsung ke program Data Science (Lau, 2019).

\section{b. Scrubbing Data}

Dalam memperoleh suatu data tidak jarang data yang diperoleh terdapat data yang nilainya hilang, inkonsistensi, kesalahan, karakter yang aneh, dan kolom yang kurang menarik. Maka diperlukan scrubbing data ataupun membersihkan data untuk memudahkan dalam melakukan analisis data jumlah penerimaan mahasiswa baru (Lau, 2019). Operasi umum pada scrubbing data yaitu (Janssens, 2019):

1) Memfilter baris data

2) Mengekstrak pada kolom tertentu

3) Mengekstrak kata-kata

4) Mengubah nilai

5) Mengatasi nilai yang hilang

6) Mengubah data dari satu format ke format lainnya

\section{c. Explore Data (Menjelajahi Data)}

Menemukan, menyusun, serta memperluas adalah suatu proses yang sangat penting dalam menjelajahi pengumpulan data. Observasi kumpulan data set dapat membantu memilih pendekatan yang terbaik dalam penelitian analisis. Maka diperlukannya pemahaman pada suatu data yang unik, seperti nilai yang tidak biasa. Pendekatan ini digunakan dalam melakukan proses generalisasi data yang diperoleh dari dataset penerimaan mahasiswa baru Universitas XYZ dan untuk meringkas suatu karakteristik utama (Dineva \& Atanasova, 2018).

\section{d. Modeling Data}

Tahap model data merupakan tahap yang paling menarik dan Hal pertama yang perlu dilakukan dalam pembuatan model data adalah mengurangi dimensi suatu kumpulan data serta memilih yang relevan yang berkontribusi pada hasil prediksi (Lau, 2019). Dalam penelitian ini menggunakan regresi dan prediksi dalam memperkirakan nilai di masa depan menggunakan dataset jumlah penerimaan mahasiswa baru dengan metode ARIMA yang diimplementasikan menggunakan software $\mathrm{R}$ (Lau, 2019).

ARIMA (Autoregressive Integrated Moving Average) merupakan suatu metode peramalan yang memanfaatkan data di masa lalu dan sekarang melalui variabel dependen yang menghasilkan peramalan jangka pendek yang akurat. Metode ARIMA diperkenalkan oleh Box dan Gwilym Jenkins tahun 1976 yang merupakan musiman dari Box-Jenkins (Indrasetianingsih et al., 2017). ARIMA merupakan statistik yang cocok untuk meramalkan secara cepat, bersifat fleksibel, dan tingkat keakuratannya efektif sehingga tepat digunakan dalam peramalan jangka pendek dan 
hanya membutuhkan data historis dalam peramalannya (Muhammad et al., 2017).

\section{Identifikasi Model ARIMA}

Mengidentifikasi model merupakan hal yang penting dalam Analysis Time Series. Di tahap ini, kestasioneran datanya di uji baik dalam variansi dan nilai rata-rata. Maka dilakukan proses identifikasi model orde AR dan MA dalam grafik ACF (Auto Correlation) dan PACF (Partial Auto Correlation) (Aminnudin, 2018).

Tabel 2. Pola ACF dan PACF

\begin{tabular}{|c|c|c|}
\hline Model & $\mathrm{ACF}$ & PACF \\
\hline $\mathrm{R}(p)$ & $\begin{array}{l}\text { Menurun secara } \\
\text { eksponensial }\end{array}$ & $\begin{array}{c}\text { Terpotong sesudah } \\
\text { lag ke- } p\end{array}$ \\
\hline MA $(q)$ & $\begin{array}{l}\text { Terpotong sesudah } \\
\text { lag ke- } q\end{array}$ & $\begin{array}{c}\text { Menurun secara } \\
\text { eksponensial }\end{array}$ \\
\hline $\begin{array}{l}\text { ARMA } \\
(p, q)\end{array}$ & $\begin{array}{c}\text { Menurun secara } \\
\text { eksponensial } \\
\text { sesudah lag ke }(q- \\
p)\end{array}$ & $\begin{array}{c}\text { Menurun secara } \\
\text { eksponensial } \\
\text { sesudah lag ke }(p- \\
q)\end{array}$ \\
\hline
\end{tabular}

\section{Model ARIMA}

Model ARIMA merupakan model univariate time series yang menggabungkan antara model AR (Autoregressive) dan model MA (Moving Average) pada data yang tidak stasioner (As'ad et al., 2017).

\section{a. AR (Model Autoregressive)}

AR adalah model yang menjelaskan variabel terikat dipengaruhi oleh variabel itu sendiri pada periode di masa lalu. Model ini dinyatakan sebagai $\operatorname{AR}(p)$ atau ARIMA $(p, 0,0)$ dan bentuk persamaan modelnya adalah (Aminnudin, 2018):

$$
Z_{t}=\emptyset_{1} Z_{t-1}+\emptyset_{2} Z_{t-2}+\cdots+\emptyset_{p} Z_{t-p}+w_{t}
$$

Keterangan,

$Z_{t} \quad$ : nilai variabel $X$ pada waktu ke- $t$,

$\emptyset_{p} \quad$ : parameter autoregressive ke- $p$,

$w_{t} \quad$ : nilai error pada saat ke- $t$.

b. MA (Model Moving Average)

MA (Model Moving Average) adalah model yang menjelaskan secara eksplisit hubungan ketergantungan antara nilai kesalahan yang berurutan. Model ini dinyatakan sebagai MA $(q)$ atau model ARIMA $(0,0, q)$ dan bentuk persamaan modelnya adalah (Aminnudin, 2018):

$$
Z_{t}=w_{t}+\theta_{1} w_{t-1}+\theta_{2} w_{t-2}+\cdots+\theta_{q} w_{t-q}
$$

Dengan,

$Z_{t} \quad$ : nilai variabel $X$ pada waktu ke- $t$,

$\theta_{q} \quad$ : parameter moving average ke- $q$,

$w_{t} \quad$ : nilai error pada saat ke- $t$.

\section{c. Model ARMA}

Model ARMA merupakan gabungan antara model AR dan MA. Bentuk fungsi ARMA yaitu $(p, q)$ atau model ARIMA $(p, 0, q)$ dan bentuknya persamaan modelnya adalah (Susanto, 2016):

$$
\begin{aligned}
Z_{t}=\emptyset_{1} Z_{t-1}+\emptyset_{2} & Z_{t-2}+\cdots+\emptyset_{p} Z_{t-p}+w_{t} \\
& +\theta_{1} w_{t-1}+\theta_{2} w_{t-2}+\cdots \\
& +\theta_{q} w_{t-q}
\end{aligned}
$$

Keterangan,

$Z_{t} \quad:$ nilai variabel $Z$ pada waktu ke- $t$,

$\emptyset_{i} \quad:$ koefisien regresi ke- $i, i=1,2,3, \ldots, p$

$\emptyset_{p} \quad:$ parameter AR ke- $p$,

$\theta_{q} \quad:$ parameter MA ke- $q$,

$\theta_{i} \quad:$ parameter model MA ke- $i, i=1,2,3, \ldots, q$

$w_{t} \quad$ : nilai error pada saat ke- $t$,

$w_{t}, w_{t-1}, w_{t-2}, \ldots, w_{t-q} \quad$ : error pada saat $t, t-1, t$ -

$2, \ldots, t-q$ dan $w_{t}$ diasumsikan White Noise dan normal.

\section{d. Model ARIMA}

Model ARIMA $(p, d, q)$ yang dimana orde $p$ menyatakan operator $\mathrm{AR}$, orde $d$ menyatakan hasil dari differencing, dan orde $q$ menyatakan operator dari MA (Aminnudin, 2018). Bentuk umum pada model ARIMA adalah (Suseno, 2017):

$$
\emptyset(B) Z_{t}=\theta(B) w_{t}
$$

Keterangan,

$$
\begin{array}{ll}
Z_{t} & : \text { nilai variabel } X \text { pada waktu ke- } t, \\
B & : \text { operator backward shift, }
\end{array}
$$

$w_{t} \quad$ : nilai error pada saat ke- $t$.

Persamaan modelnya adalah:

$$
\begin{aligned}
Z_{t}=\left(1+\emptyset_{1}\right) Z_{t-1} & +\left(\emptyset_{1}-\emptyset_{2}\right) Z_{t-2}+\cdots \\
& +\left(\emptyset_{p}-\emptyset_{p-1}\right) Z_{t-p}+w_{t} \\
& -\theta_{q} w_{t-1}-\cdots-\theta_{q} w_{t-q}
\end{aligned}
$$

Keterangan,

$Z_{t} \quad$ : nilai variabel $X$ pada waktu ke- $t$,

$\theta_{q} \quad$ : parameter moving average ke- $q$,

$\emptyset_{p} \quad$ : parameter autoregressive ke- $p$,

$w_{t} \quad$ : nilai error pada saat ke- $t$.

\section{Estimasi Parameter}

Estimasi parameter dapat dilakukan dengan menggunakan beberapa cara yaitu, least square, unconditional least square, moment, dan maximum likelihood (Susanto, 2016).

\section{Pengujian Signifikansi Parameter}

Pengujian signifikansi parameter dapat dilakukan dengan uji $t$. Hipotesis yang digunakan pada pengujian model AR ( $p)$ adalah (Susanto, 2016):

$\mathrm{H}_{0}: \emptyset_{i}=0, \forall_{i}$

$\mathrm{H}_{1}: \emptyset_{i} \neq 0, \exists_{i}$ untuk $i=1,2, \ldots, p$

Statistik uji parameternya adalah: 


$$
t=\frac{\widehat{\emptyset}_{i}}{S E\left(\widehat{\emptyset}_{i}\right)}
$$

Pengujian signifikansi parameter pada model MA (q) adalah (Susanto, 2016):

$\mathrm{H}_{0}: \theta_{i}=0, \forall_{i}$

$\mathrm{H}_{1} \quad: \theta_{i} \neq 0, \exists_{i}$ untuk $i=1,2, \ldots, q$

Statistik uji parameternya adalah:

$$
t=\frac{\hat{\theta}_{i}}{S E\left(\hat{\theta}_{i}\right)}
$$

\section{Pengujian Asumsi Residual}

Untuk mendapatkan model ARIMA yang terbaik, ada beberapa asumsi yang harus dipenuhi pada residual yaitu White Noise dan uji distribusi normal (Susanto, 2016).

a. Uji White Noise

Dalam pengujian White Noise dapat menggunakan uji Box-Pierce Modified atau Ljung-Box.

b. Uji Asumsi Distribusi Normal

Uji asumsi distribusi normal dilakukan untuk mengetahui residual berdistribusi normal atau tidak.

\section{Forecast (Peramalan)}

Untuk melakukan peramalan fungsi yang dapat digunakan adalah fungsi forecast() untuk 5 tahun ke depan dengan model yang terbaik. Tahap dalam peramalan terdiri dari 3 macam yaitu training, testing, dan forecasting untuk 5 tahun ke depan dengan fungsi autolayer(). Data training adalah peramalan yang menggunakan data asli, data testing adalah peramalan yang tidak menggunakan data asli, sedangkan forecasting adalah hasil peramalan. Langkah-langkah forecasting pemodelan data ARIMA di software R (Raymond, 2018):

a. Exploratory Data Analysis

Menjelajahi dan memvisualisasikan data frame dengan menggunakan fungsi ggplot(). Selanjutnya mengubah data frame menjadi data time series serta menampilkan plot data penerimaan mahasiswa baru dengan menggunakan fungsi plot()

b. Decomposing the Data (dekomposisi data)

Proses dekomposisi data dilakukan untuk memeriksa adanya suatu trend, seasonal, dan random komponen.

c. Test Stationary (Tes Stasioneritas)

Time series dapat disebutkan stasioner dengan syarat mean, variance, dan covariance bukan merupakan fungsi waktu. Tes stasioneritas dapat dilakukan dengan menggunakan fungsi adf.test ().

d. Identifikasi Model

Setelah data stasioner selanjutnya adalah melihat plot ACF (Autocorrelation) fungsi yang digunakan adalah fungsi $a c f()$. Untuk melihat plot PACF (Partial Autocorrelation) fungsi yang digunakan adalah $\operatorname{pac} f()$. e. Membuat model ARIMA terbaik

Dalam melakukan perhitungan model ARIMA fungsi yang dapat digunakan adalah fungsi auto.arima(). Pemilihan model terbaik dapat dilihat melalui nilai AIC dan SBC/BIC pada hasil dari proses membuat model.

f. Estimasi Model

Untuk mengetahui apakah model signifikan atau tidak dengan menggunakan fungsi coeftest().

g. Uji asumsi residual/diagnostik

Untuk melakukan pemeriksaan apakah model ARIMA sudah fit dengan residual fungsi yang dapat digunakan adalah fungsi ggtsdiag() dan packages yang diperlukan adalah packages ggfortify.

\section{Interpreting Data (Menafsirkan Data)}

Interpretasi data merupakan tahap terakhir dan tahap paling penting di model OSEMN (Lau, 2019). Interpretasi hasil penelitian penting untuk memahami efektivitas penelitian dan mendeskripsikan secara jelas hasil perbandingan penelitian sendiri dengan penelitian lain (Dineva \& Atanasova, 2018).

\section{HASIL DAN PEMBAHASAN}

Hasil analisis dari penelitian ini dilakukan dengan menggunakan bantuan software R 4.0.2. Software ini digunakan untuk menganalisis dan meramalkan jumlah penerimaan mahasiswa baru dengan menggunakan model ARIMA. Dataset yang digunakan dalam penelitian sebanyak 9611 data yaitu data jumlah penerimaan mahasiswa baru Universitas XYZ dari tahun 2010 sampai 2019.

\section{Exploratory Data Analysis}

Dataset jumlah mahasiswa baru yang sudah bersih dapat digunakan untuk memvisualisasikan data dalam berbagai macam bentuk plot yang termasuk dalam langkah awal dari Exploratory Data Analysis untuk melihat bagaimana perbandingan jumlah mahasiswa baru di masa lampau dan di masa depan.

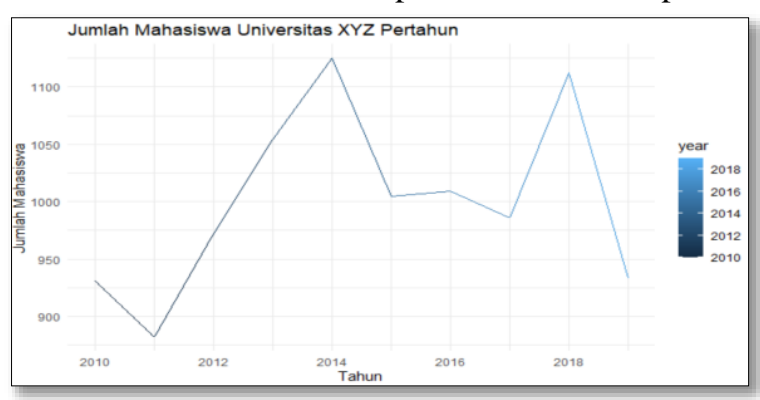

Gambar 2. Plot data penerimaan mahasiswa baru per tahun

Berdasarkan Gambar 2. terlihat bahwa plotnya merupakan plot data yang fluktuatif. Plot data tersebut diambil dari jumlah penerimaan mahasiswa 
baru Universitas XYZ per tahun dalam jangka 10 tahun yaitu mulai dari tahun 2010 hingga 2019. Pada plot penerimaan mahasiswa baru keseluruhan Universitas XYZ terdapat penurunan pada tahun 2011 kemudian mengalami peningkatan yang melonjak hingga tahun 2014, lalu turun kembali hingga tahun 2017 dan mengalami peningkatan lagi di tahun 2018 kemudian turun kembali di tahun 2019. Jumlah mahasiswa tertinggi terjadi pada tahun 2014 dengan jumlah 1125 dan jumlah mahasiswa terendah terjadi pada tahun 2011 dengan jumlah 882. Jumlah mahasiswa baru yang naik turun menyebabkan ketidakstabilan dan tidak konstan terhadap suatu nilai tertentu pada jumlah mahasiswa baru.

\section{Forecast jumlah mahasiswa baru Universitas XYZ}

\section{a. Plot data}

Langkah awal dalam pemodelan ARIMA adalah memplot data. Berdasarkan Gambar 3. plot data time series jumlah penerimaaan mahasiswa baru keseluruhan Universitas XYZ menunjukkan bahwa plot data time series sudah terlihat stasioner dalam mean dan variance maka asumsi metode ARIMA telah terpenuhi. Data time series diperoleh dari data training yang mana jumlah data yang digunakan untuk periode training sebanyak 8709 data dan data testing sebanyak 902 data.

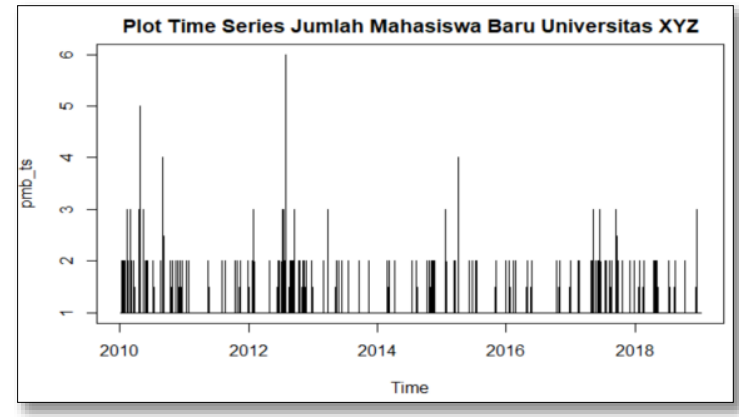

Gambar 3. Plot data time series Universitas XYZ

\section{b. Decomposing the Data (dekomposisi data)}

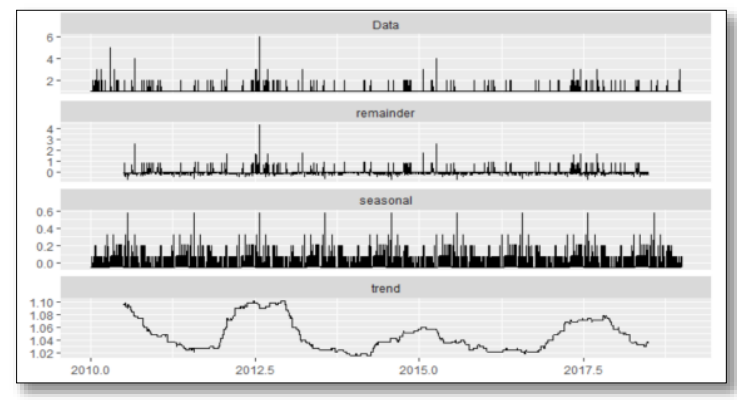

Gambar 4. Plot data, remainder, seasonal, dan trend

Berdasarkan Gambar 4. sudah terlihat plot data mahasiswa baru, pola seasonal, dan trend yang mengalami kenaikan dan penurunan yang tidak stabil, dan komponen random di bagian "remainder" dari dataset jumlah mahasiswa baru keseluruhan Universitas XYZ.

\section{c. Test Stationary (Tes Stasioneritas)}

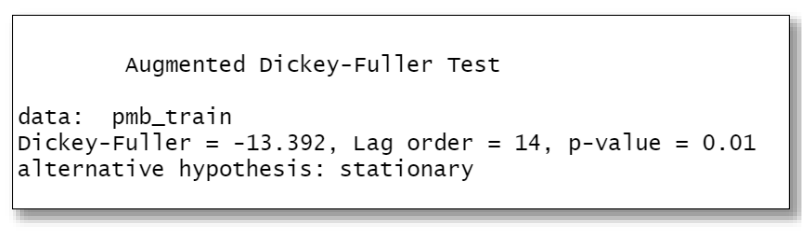

Gambar 5. Tes stasioneritas

Berdasarkan Gambar 5. didapatkan kesimpulan yang sama juga diperoleh dari hasil uji ADF (Augmented Dickey Fuller) yang mana nilai p-value $=0.01$ yang nilainya lebih kecil dari nilai alpha yaitu $5 \%(0,05)$ maka $\mathrm{H}_{0}$ ditolak, sehingga artinya data tersebut sudah stasioner dengan demikian data time series dapat digunakan untuk membuat model ARIMA.

Berikut adalah summary dari data:

\begin{tabular}{|rrrrrr}
\hline Min. 1 1st Qu. & Median & Mean 3rd Qu. & Max. \\
1.000 & 1.000 & 1.000 & 1.051 & 1.000 & 6.000 \\
\hline
\end{tabular}

Gambar 6. Summary data

Berdasarkan Gambar 6. dapat dilihat dalam kurun waktu 10 tahun, rata-rata jumlah mahasiswa mendaftar setiap harinya berjumlah 1 mahasiswa.

\section{d. Identifikasi Model ARIMA}

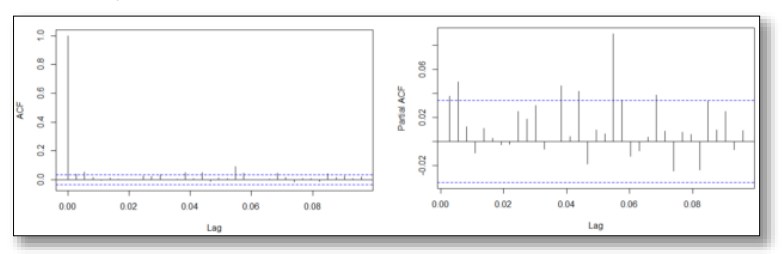

Gambar 7. Plot ACF dan PACF

Berdasarkan Gambar 7. plot ACF menunjukkan bahwa terdapat 2 lag yang keluar yang artinya mengandung moving average atau $\mathrm{MA}(0)$ dan MA(1), Sedangkan untuk plot PACF menunjukkan bahwa terdapat 2 lag yang keluar yang artinya mengandung autoregressive atau $\mathrm{AR}(1)$ dan $\mathrm{AR}(2)$. 


\section{e. Membuat model ARIMA}

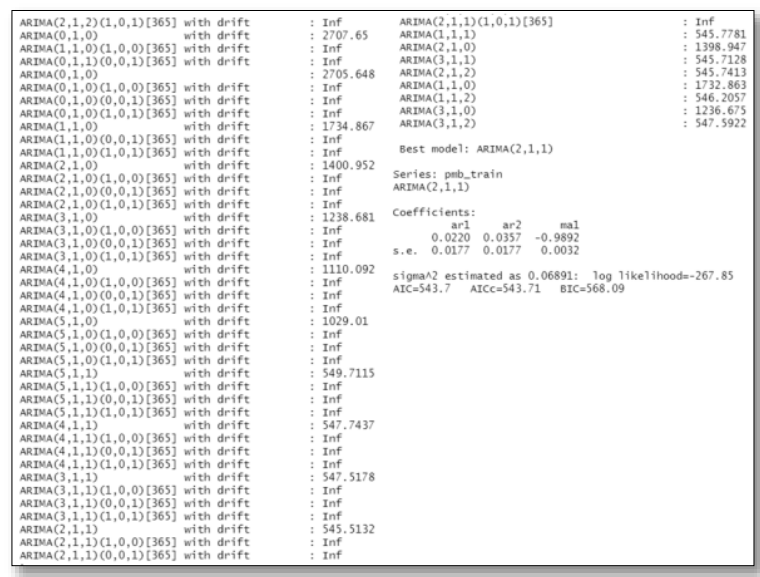

Gambar 8. Membuat model ARIMA dengan auto.arima

Dari plot ACF dan PACF di atas didapatkan model ARIMA terbaik dengan menggunakan auto.arima yaitu model ARIMA (2,1,1). Model ini dikatakan best model (model terbaik) karena nilai AIC, likelihood, dan MAPE lebih kecil dibandingkan dengan nilai model yang lain sehingga model ARIMA $(2,1,1)$ dapat dikatakan model terbaik dan dapat dilakukan peramalan jumlah mahasiswa baru keseluruhan Universitas XYZ dengan model tersebut seperti yang terlihat pada Gambar 8 .

\section{f. Estimasi Model ARIMA}

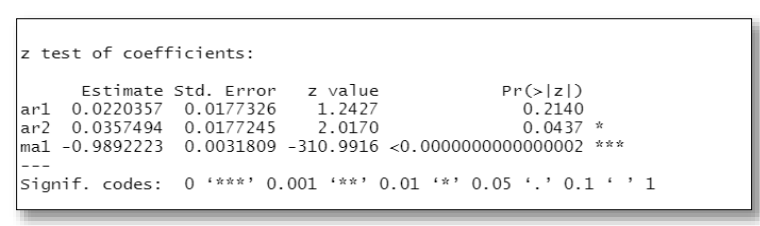

Gambar 9. Cek signifikan model ARIMA

Berdasarkan Gambar 9. dapat dilihat bahwa semua estimasi nilai signifikannya p-value $<0,05$. Sehingga didapatkan model yang signifikan yaitu ARIMA $(2,1,1)$ untuk peramalan 5 tahun ke depan.

\section{g. Uji Diagnostik}

Selanjutnya dilakukan uji diagnostik residual data. Berikut hasil dari uji diagnostik residual model ARIMA $(2,1,1)$ :

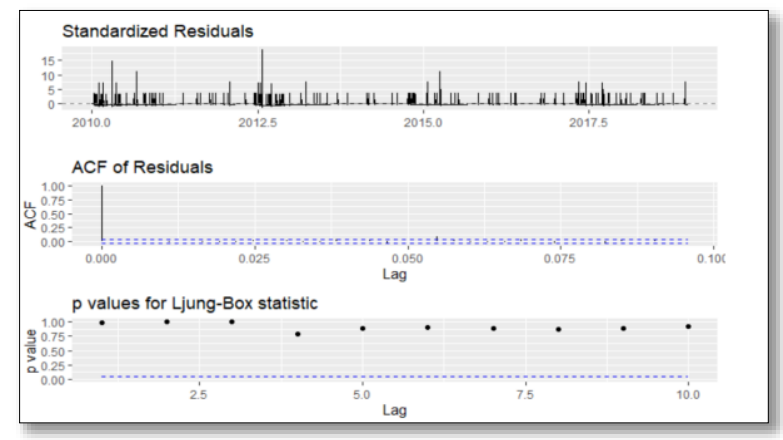

Gambar 10. Uji diagnostik
Berdasarkan Gambar 10. dapat dilihat plot ACF residual data merupakan model white noise karena tidak terdapat lag yang keluar dari garis batas interval. Model terbaik merupakan model yang memenuhi syarat signifikan parameter sehingga model ARIMA $(2,1,1)$ secara fair dikatakan good fit atau sebagai model terbaik dalam prediksi jumlah mahasiswa baru keseluruhan Universitas XYZ. Sedangkan dilihat dari plot p-value ada yang lebih dari $\alpha=0,05$ yang artinya tidak terdapat autokorelasi pada data sehingga asumsi nonautokorelasi terpenuhi. Maka model $(2,1,1)$ cocok digunakan untuk peramalan jumlah mahasiswa baru keseluruhan Universitas XYZ periode 2020-2024.

\section{h. Forecast}

Langkah terakhir dalam analisis time series adalah melakukan peramalan untuk 5 tahun ke depan. Maka didapatkan plot forecasting mahasiswa baru sebagai berikut:

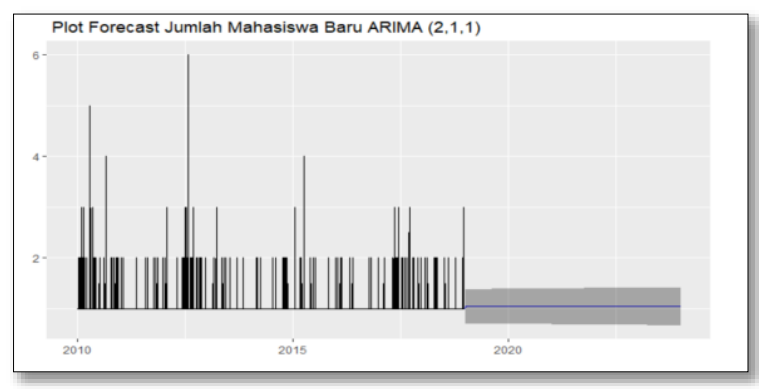

Gambar 11. Plot hasil forecast Universitas XYZ

Berdasarkan Gambar 11. dapat dilihat bahwa hasil peramalan jumlah mahasiswa baru keseluruhan Universitas XYZ akan mengalami penurunan yang merata. Dapat dilihat bahwa ada trend penurunan jumlah mahasiswa baru per hari untuk 5 tahun ke depan. Agar penerimaan mahasiswa baru keseluruhan Universitas XYZ mengalami peningkatan, maka dapat dilakukan antisipasi dengan melakukan perencanaan promosi yang lebih baik lagi sehingga dapat menarik minat mahasiswa untuk mendaftar.

Setelah model diperoleh, selanjutnya yaitu meramalkan menggunakan training data yang mana jumlah data yang digunakan untuk periode training adalah sebanyak 8709 yaitu data pada tahun 20102018 dan untuk periode testing sebanyak 902 data yaitu data pada tahun 2018-2019. 


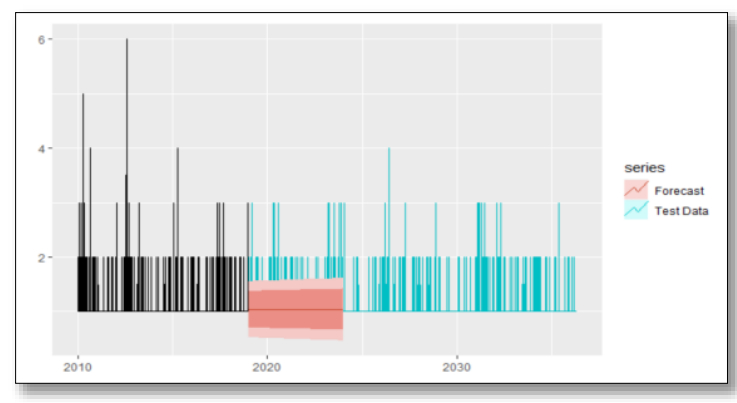

Gambar 12. Perbandingan plot train data, test data, dan forecast

Berdasarkan Gambar 12. terlihat plot train data berwarna hitam, plot test data berwarna hijau, serta pada plot forecast berwarna peach. Peramalan jumlah mahasiswa baru dengan model ARIMA $(2,1,1)$ cenderung menurun dengan rata-rata jumlah mahasiswa yang mendaftar setiap harinya yaitu 1 mahasiswa. Jadi dapat disimpulkan bahwa jumlah mahasiswa baru untuk 5 tahun ke depan mengalami penurunan.

Berikut merupakan nilai MAPE dari hasil forecasting penerimaan mahasiswa baru keseluruhan Universitas XYZ:

Training set error measures:
ME RNSE MAE MPE MAPE MASE ACF1 Training set $-0.0019192970 .26234450 .09699969-2.8257517 .066147 \quad 1.018846-0.0002155975$

Gambar 13. Nilai MAPE forecast Universitas XYZ Berdasarkan Gambar 13. didapatkan nilai MAPE 7.066147 dengan nilai akurasi sebesar 93\% yang berarti bahwa kesalahan dari model yang digunakan sangat kecil karena nilainya di bawah $10 \%$ sehingga hasil peramalan dikatakan sangat akurat.

\section{KESIMPULAN}

Berdasarkan hasil analisis peramalan yang telah dilakukan maka dapat disimpulkan bahwa proses analisis time series menggunakan metode ARIMA memberikan model ARIMA terbaik untuk peramalan jumlah mahasiswa baru keseluruhan Universitas XYZ yaitu ARIMA $(2,1,1)$.

Hasil peramalan jumlah mahasiswa baru untuk 5 tahun ke depan yaitu mulai dari 2020 hingga 2024 dengan menggunakan metode ARIMA menunjukkan bahwa terjadinya trend penurunan jumlah mahasiswa baru secara merata dengan nilai kesalahan atau nilai MAPE sebesar 7.066147 dengan akurasi sebesar 93\% yang berarti model bisa digunakan untuk meramalkan jumlah mahasiswa baru dengan sangat akurat.

Dari hasil analisis peramalan disarankan untuk penelitian selanjutnya diharapkan dapat mengkombinasikan metode ARIMA dengan metode machine learning yang lain agar tingkat akurasi permalan menjadi lebih baik lagi.

\section{REFERENSI}

Achmanda, A. D. (2018). Peramalan Jumlah Penderita Penyakit Demam Berdarah Dengue ( DBD ) Menggunakan Metode ARIMA. Skripsi Sarjana.

http://repositori.usu.ac.id/handle/123456789/1 2377

Aminnudin, Y. F. (2018). Penerapan Filter Kalman Dalam Perbaikan Hasil Prediksi Return Harga Minyak Mentah Dunia Dengan Model ARIMA (Vol. 10, Issue 2).

As'ad, M., Wibowo, S. S., \& Sophia, E. (2017). Peramalan Jumlah Mahasiswa Baru Dengan Model Autoregressive Integrated Moving Average (Arima). J I M P - Jurnal Informatika Merdeka Pasuruan, 2(3), 20-33. https://doi.org/10.37438/jimp.v2i3.77

Dineva, K., \& Atanasova, T. (2018). Osemn Process for Working Over Data Acquired By Iot. Current Trends in Natural Sciences, 7(13), 47-53.

Indrasetianingsih, A., Damayanti, I., \& Susanto, T. (2017). Analisis ARIMA Box Jenkins untuk Peramalan Jumlah Kunjungan Wisatawan Mancanegara di Indonesia. Seminar Nasional Matematika Dan Aplikasinya, 226-229.

Irawan, W. (2019). Peramalan Harga Saham PT.Unilever Tbk dengan Menggunakan Metode ARIMA. Jurnal Matematika UNAND, 4(3), 80. https://doi.org/10.25077/jmu.4.3.8089.2015

Janssens, J. (2019). Data Science at the Command Line. $\quad 08 \quad$ Oktober. https://www.bookstack.cn/read/data-scienceat-the-commandline/spilt.2.906470b2bf1cf715.md\#1.2.1 Obtaining Data

Lau, D. C. H. (2019). 5 Steps of a Data Science Project Lifecycle. 3 Januari. https://towardsdatascience.com/5-steps-of-adata-science-project-lifecycle-26c50372b492

Muhammad, M., Harjono, \& Akhsani, L. (2017). Peramalan Mahasiswa Baru FT dan FKIP UM Purwokerto Dengan Model Arima. Journal Techno, 18(2), 123-132.

Ningsih, S. C., \& Jana, P. (2018). Pemodelan Penderita HIV / AIDS dengan Metode ARIMA. Jurnal Penelitian Matematika Dan Pendidikan Matematika, 3(1), 23-28.

Niswatin, R. K. (2016). Sistem Seleksi Penerimaan Mahasiswa Baru Menggunakan Metode Weighted Product ( Wp ). Seminar Nasional Teknologi Informasi Dan Multimedia 2016, 31-36.

Raymond. (2018). Enlightening Indonesian Data Scientists. $03 \quad$ November. https://www.raymond4ds.com/2018/11/timeseries-modelling-arima-step-by-step.html 
Susanto, Y. (2016). Pemodelan Curah Hujan dengan Pendekatan Model ARIMA, Feed Forward Neural Network dan Hybrid (ARIMA-NN) di Banyuwangi. Jurnal Sains Dan Seni ITS, 5(2), 145-150.

Suseno, S. W. (2017). Penerapan Metode Arima Box-Jenkins Untuk Peramalan Pasien Rawat Jalan Di Rsud Kartini Kabupaten Jepara Berbantuan Eviews. Skripsi. https://lib.unnes.ac.id/32221/

\section{PROFIL PENULIS}

Ayu Ulfa Jamila, lahir di Tasik Raja pada 18 September 1999. Mahasiswa semester VII Program Studi Sistem Informasi STMIK Mikroskil Medan.

Bella Merlin Siregar, lahir di Kisaran pada 04 April 1999. Mahasiswa semester VII Program Studi Sistem Informasi STMIK Mikroskil Medan.

Roni Yunis, lahir di Bukittinggi pada 19 April 1975. Dosen Tetap di Program Studi Sistem Informasi STMIK Mikroskil Medan. 